\title{
Community-Based Participatory Research with Invisible, Geographically-Dispersed Communities: Partnering with Lesbian, Gay, Bisexual, Transgender and Queer Communities on the California Central Coast
}

\author{
Laury Oaks \\ Department of Feminist Studies, UC Santa Barbara \\ Tania Israel
}

Department of Counseling, Clinical, and School Psychology, The Gevirtz School, UC Santa Barbara

\author{
Kristin J. Conover \\ California School of Professional Psychology \\ Alise Cogger \\ Keck School of Medicine, University of Southern California \\ Todd Raymond Avellar \\ Clinical-Community Psychology Program, Point Park University
}

\begin{abstract}
This article reports on the community-based participatory research (CBPR) process of a 3.5-year study documenting lesbian, gay, bisexual, transgender, and queer (LGBTQ) community members' perceptions of local LGBTQ communities on the Central Coast of California. This three-phase study consisted of online and paper-and-pen surveys to analyze community strengths, challenges, priorities, and feelings of connection; collaborative interpretation of survey results through community forums; and a regional "LGBTQ Summit" to envision and initiate data-based actions to address community priorities. The focus throughout the project was on establishing collaborative partnerships to plan and guide the project, cultivating community participation in interpreting and disseminating findings, and honoring diverse LGBTQ community members' voices through data-driven community action. This article documents lessons learned about building and facilitating community-university partnerships, organizing and maintaining a sustained community research collaborative, engaging community participation, and ultimately, creating lasting, community-driven interventions.
\end{abstract}

Keywords: community-based participatory research; LGBTQ communities; marginalized communities; minority stress; community collaborations

(C) 2019 Oaks, Israel, Conover, Cogger, \& Avellar. Free to copy and share for education and scholarship under a Creative Commons Attribution NonCommercial-NoDerivatives 4.0 License. 


\section{Introduction}

Community-based participatory research (CBPR) provides a framework for identifying community assets and concerns, and motivates campus and community partners together to focus on relevant, targeted service interventions (Minkler \& Hancock, 2003; see also Israel et al., 2005; Minkler, 2005; Minkler \& Wallerstein, 2008 Wallerstein \& Duran, 2006; Wells \& Norris, 2006). Actively engaging community members alongside health, mental health, and social services providers in research conceptualization and assessment of problems signaled in collected data ensure that research aims and conclusions reflect community needs.

Recently, CBPR has been used with diverse lesbian, gay, bisexual, transgender, and queer (LGBTQ) communities to understand and improve health-related inequities, discrimination, and outcomes (Bauermeister et al., 2017; Marshall et al., 2012; Rhodes et al., 2014; Rodriguez-Diaz et al., 2016; Tanner et al., 2016; Travers et al., 2013), employment outcomes (Hergenrather, Geishecker, Clark, \& Rhodes, 2013), and risk factors for suicidal ideation (Irwin, Coleman, Fisher, \& Marasco, 2014). Researchers have found CBPR to be particularly useful with LGBTQ communities because it takes into account current and historical feelings of mistrust toward research institutions, adheres to an ethos of "cultural humility," integrates community norms and language, and increases diversity among planning and participants (Bauermeister et al., 2017). To foster positive, lasting change within LGBTQ communities; therefore, integration of the community in research is essential for culturally congruent actions and recommendations.

The psychological literature includes a limited number of articles outlining lessons learned from CBPR projects with specific LGBTQ subpopulations, such as sexual and gender minority youth (Bauermeister et al., 2017), African American gay men living with HIV/AIDS (Hergenrather et al., 2013), LGBTQ youth with intellectual disabilities (Marshall et al., 2012), Guatemalan sexual minority men and transgender people (Rhodes et al., 2014), and the trans community in Ontario, Canada (Travers et al., 2013). To the authors' knowledge, however, no literature exists presenting an in-depth discussion of the unique aspects of conducting CBPR with a diverse and geographically-defined LGBTQ community. This is an essential type of community to understand because service agencies are often in the position of trying to meet the needs of a wide range of LGBTQ individuals living in a broad region. This article fills that gap.

The authors participated in a 3.5-year CBPR project with LGBTQ communities in the Central Coast region of California. In this region, these communities are geographically-dispersed and often invisible. CBPR has been conducted with members of LGBTQ populations that are not centered on a particular neighborhood or urban location (Dobinson et al, 2005; Graziano, 2004; Paxton, Guentzel \& Trombacco, 2006; Rhodes, Yee \& Hergenrather, 2006; Willging, Salvador, \& Kano, 2006; Clements-Nolle \& Bachrach, 2008). Our choice of CBPR is mindful of the unique and potentially powerful role community plays for LGBTQ individuals, even when not centered on common geographic space, sometimes known as a "gayborhood."

Given the complexity of factors that influence how members of a group perceive their community and their relationship to it, researchers should work with diverse individuals to encourage representation of those who feel connected to the LGBTQ community in different ways. The experience of living with stigma, prejudice, discrimination, and violence against LGBTQ people creates minority stress in this population (Meyer, 2003). Social support can buffer the negative consequences of minority stress for LGBTQ individuals (Friedman et al., 2006; Lehavot, Balsam and Ibrahim-Wells, 2009; Peterson, Folkman, and Bakeman, 1996; Szymanski \& Kashubeck-West, 2008), and support can be provided at the individual, group and community levels. Despite the shared experience of social marginalization and the need for support among LGBTQ individuals, considerable differences exist among LGBTQ individuals that create challenges for community cohesiveness. Diversity within LGBTQ communities that may influence "belonging" includes sexual orientation identity, gender expression, age, race/ethnicity, level of integration within the heterosexual community, relationship status, and degree of "outness."

Our research was attentive to other types of diversities characterizing the local area. We conducted 
our project in a county divided by a mountain range into distinct north and south regions. The county is comprised of eight incorporated cities with a total population of over 400,000 residents (U.S. Census Bureau, 2006). The southern county is located on the Pacific coast, hosts tourist and technology industries, and has a significant research university. The northern county is primarily inland, with major employment opportunities in agriculture, at an Air Force Base or a federal prison complex, or commute to work. At the end of the project in February 2010, the median home list price in the largest South county city was $\$ 1.2$ million versus a median home list price of $\$ 250,000$ in the most populated North county city (Zillow, 2018). Further demonstrating contrasts in the character of two parts of the county, there were more people of color in the North county compared to the South; for example, $42 \%$ of the North county and $28 \%$ of the South county population identified as Latino (U.S. Census Bureau, 2006).

At the time of this project, there was no LGBTQ-specific gathering space in the county, such as a gay bar, coffee shop, bookstore, or community center. LGBTQ community members in the region noted the dearth of public, social meeting spaces and reported feeling threatened by local incidents of harassment and violence against LGBTQ individuals (Israel, et al., 2008; Tennant-Moore, 2007). The primary provider of mental health and social support services for LGBTQ communities in the region has its headquarters in South county and an office in North county. Further, the agency received much of their funding in order to provide services for people with HIV/AIDS, and had very limited resources for services for LGBTQ individuals who are not HIV+.

This article documents the planned and unexpected parts of conducting CBPR within an invisible community that covers a large geographic area and does not have much cohesion, collective voice, visibility, or infrastructure. We begin with descriptions of the community-academic relationships and the three phases of data-driven action. Our analysis of strengths, challenges, and strategies addresses each stage of the project, roles, and relationships among project components, attention to diversity within LGBTQ communities, and efforts to sustain the project.

\section{Community-Academic Relationships}

Our community-based participatory research (CBPR) project was initiated when the first and second authors, both university faculty, approached the Executive Director and Director of Counseling at the local LGBTQ non-profit agency. We discussed the idea of collaborating on a CBPR project related to mental health concerns for local LGBTQ communities, drawing on the second author's expertise in LGBTQ mental health and the first author's research on community health perceptions. The LGBTQ agency administrators shared anecdotal knowledge about LGBTQ individuals' requests for services and the lack of an adequate study of community resources and needs. We sought to cultivate community members' investment in all study phases, including planning, implementation, and data interpretation.

Our first step toward gaining community participation was a series of group meetings at which LGBTQ community members offered project development input. Participants highlighted community concerns, such as invisibility and isolation, as well as a lack of dedicated LGBTQ spaces for socializing. Despite our initial efforts to invite a broad base of community members to design a CPBR project, there was a noted absence of individuals who were not in professional LGBTQ services and advocacy positions, leading one participant to light-heartedly to refer to the group as composed of "professional queers." We realized that it is logical that the first people to step up to participate are professionals, many of whom are too busy to devote time to a CBPR project. We immediately modified our community contact strategy and solicited the assistance of our community partner organization to help us connect with a broader audience. These efforts were successful, and we achieved the participation of community members in each aspect of the project, the majority being nonprofessionals.

At this early stage, Israel and Oaks established a research team with graduate students in counseling 
psychology and an Executive Committee (EC) consisting of themselves and the collaborating LGBTQ agency staff. The EC initiated the development of a Partnership Council composed of community, EC, and research team members who would work together to plan and implement the project. The Executive Committee met bi-weekly to provide leadership and resources by planning monthly Council meetings and developing grant proposals. Our aim was to assemble a Council that provided broad LGBTQ community representation based on professional and community roles as well as social identities and county-wide geographic locations. In order to identify constituencies essential to the successful collaborative planning and implementation of the research, research team members created a database of LGBTQ community resources and groups and conducted informal interviews with community members in LGBTQ organizations and communities (transgender, youth, and Latinx).

The Council met monthly to provide input on grant opportunities, survey development, and continued development of the group. Demonstrating collaboration, a university research team member sent meeting information to Council members and organized the RSVPs, and LGBTQ service organization staff reserved meeting space. At meetings, a research team member took notes, which were reviewed by two EC members before being distributed to Council members via email. The major Council work was completed in person at these meetings; other than communication about the meetings, email or phone discussions were minimal. Attendance averaged around eight people at each meeting, with a more consistent presence of some. Each meeting included at least one research team and one EC member. We limited the number of research team members so the community members would have a dominant voice in the process.

We first formed two groups, one meeting in North and the other in South county, with quarterly joint meetings. This was logistically difficult because we did not have the capacity to maintain two different research projects. Following our partner agency's guidance, we recognized that the North and South county LGBTQ residents had different needs and goals - community-building and integration into institutional infrastructures, respectively - and we continued to attend to these. We merged the two groups and rotated meetings among three locations, which had the benefits of directing South county resources to North county CBPR activities and promoting countywide community-building efforts. This change seemed to meet most Council member's needs, although it led to one member leaving the Council disgruntled. The Council set a regular evening monthly meeting time and agreed to a policy of canceling a meeting that had fewer than three RSVPs from Council members. The multiple-location strategy, carpools, and shared meals at the meetings enhanced our relationships and the collaborative community feeling of the Council.

Early in the Council development, a few vocal members expressed impatience with the ambiguity of the process; they urged the researchers to make project decisions and lead the group. This conflict was not directly resolved, although this sentiment seemed to dissipate as the project took form. To promote the project's growth, we devoted extensive time and energy to the development and support of the Council, following other scholars' experiences of successful CBPR studies and "lessons learned" (CCPH, 2000; Minkler \& Hancock, 2003; Becker, Israel, \& Allen 2005; Minkler, 2005; Minkler \& Wallerstein, 2008). Council members reflected diversity in terms of gender, gender identity/expression, economic status, ethnic group membership, culture, age, HIV status, mental health consumer status, and physical abilities. To promote diversity and enhance trust, EC and Council members personally invited others to join the group. A particular challenge we faced is that the LGBTQ community is small, with many relationship interconnections and differing degrees of "outness" amongst its members. We took care to invite members who would work well with others on the Council and be comfortable with visibly being part of an LGBTQ project. At the same time, we were aware that our sensitivity to maintaining positive group dynamics and LGBTQ-community affiliation did bar some individuals from participating.

The membership of the Council, EC, and research team changed over time in keeping with individuals' availability, interest, and energy. We faced particular difficulty developing a Council representative of diverse constituencies that allowed disenfranchised individuals to share an equal voice with more privileged members. 
We were more successful recruiting service providers and established, visible LGBTQ community members to the Council.

Drawing on models from CBPR research, the EC developed a Partnership Agreement to articulate a set of principles to guide the project; all EC, Council, and research team members read and signed the Partnership Agreement (available upon request of the first author). This provided new members with a clear sense of the responsibilities of Council membership. However, the Agreement was not designed by the Council as a whole. This indicates that some forms of leadership power were retained by the EC. In part, this lack of power-sharing was created because the early Council consisted of several vocal members who wanted to take action, not process ideas. In retrospect, forming a Partnership Agreement Committee of the Council could have more readily shared power between the EC and Council.

\section{Data-Driven Action in Three Phases}

Several phases of this project entailed collecting and/or sharing data with the community to inform action: 1) conducting a survey of LGBTQ community assets and risks, 2) gathering additional community input via forums, and 3) convening a regional LGBTQ Summit. These aspects of data-driven action built on one another and resulted in several initiatives. Here, we explain each phase, followed by an analysis of the challenges we encountered and the strategies we used.

\section{Phase 1: Survey of Community Assets and Risks}

Early in the project, our community partner and service providers expressed a desire to know more about how local LGBTQ people perceive the LGBTQ community, especially in light of the community's dearth of gathering spaces and limited visibility. In response to this interest, Phase 1 was a survey to assess LGBTQ community assets and concerns. Close to 400 community members responded to our online or paper survey that included open- and closed-ended questions about the psychological sense of community, social support, community involvement, descriptions of community, priorities, and aspects of the community they would like to change or retain.

The survey was designed within a collaborative CBPR framework, and the division of responsibilities drew on the strengths of the collaborators. The EC planned and guided all aspects of the survey, including coordinating and assigning tasks and making administrative decisions. The research team reviewed scholarly literature, consulted with experts in CBPR survey development, and disseminated information to the EC and Council. The research team also assisted the data collection by recruiting participants and distributing surveys. The Council provided input on survey development and data collection, including a selection of topics, wording of items, and participant recruitment.

Because LGBTQ people in this county typically do not live in a cohesive neighborhood setting and may not be easily identifiable, we used multiple approaches to recruit survey participants from this hidden, scattered population. Given the absence of local gathering places and infrequent LGBTQ community activities, the Internet is a primary means of connection and communication among local LGBTQ individuals. Therefore, we initially recruited Internet survey respondents through electronic mailing lists and websites that provided information about local LGBTQ activities.

After a preliminary analysis of data from a significant number of surveys $(n=291)$, we identified segments of local LGBTQ communities that were underrepresented in our sample, including youth, transgender individuals, primarily Spanish-speaking people, older adults, rural residents, and North County residents. In response, we implemented a targeted recruitment strategy that included the distribution of paper surveys and a link to the online survey through community events, community researchers, and service providers. Consistent with strategies implemented in other CBPR (e.g., Clements-Nolle \& Bachrach, 2008), the research team hired and trained three community researchers from particularly hard to reach segments of local LGBTQ communities to assist in data collection. The training included handouts, a demonstration of survey completion, role-plays, and 
a quiz. Following the training, the community researchers distributed 50-60 paper surveys through personal networks, private gatherings, and public events. They offered interviews as an alternative option for participants, although no participants opted to provide information in this way. As an incentive and to respect their research work, community researchers were paid for their time and for each survey returned.

\section{Phase 2: Community Forums}

Relying on CBPR principles that emphasize the importance of community participation in each aspect of research, the Council decided to host community forums to share survey results and gather input for collaborative interpretation of results and identification of areas for community growth. To that end, the Council hosted nine 2-hour LGBTQ Community Forums, ranging in size between five and 23 participants, with 83 participants total. The forum format was based on a modified version of the Collaborative Change Approach, which relies on facilitated, interactive discussions with stakeholder groups and is particularly valuable because it helps multiple parties collaborate in the creation and implementation of lasting organizational or community change (e.g., Fountain \& Evans, 1994; Ridley, 1997). Forum participants were recruited through the same avenues used for the survey. In addition, survey participants who expressed interest in continued involvement in the project were emailed. Council members recruited participants through personal, professional, and informal social networks.

To capture a range of perspectives, we arranged five of the forums to focus on specific affinity groups: people of color, transgender individuals, primarily Spanish-speaking community members, students, and college faculty and staff. The remaining forums were open to all LGBTQ-identified individuals who reside, work, and/or socialize in the county. Forums were held in the north and south parts of the county to capture regional diversity. Participants were provided with refreshments and were entered in a drawing for a $\$ 25$ gift certificate. In order to maintain confidentiality and increase participants' feelings of safety, participants were not asked to provide any identifying or demographic information.

The forums were designed and facilitated by a local organization that specialized in training on inclusion and equity, and research team members participated by presenting survey data and taking notes. Following an opening activity to help participants envision a healthy LGBTQ community, facilitators provided survey results verbally and visually, using a PowerPoint presentation. Participants identified what resonated and what was missing based on their experiences and perspectives. At the end of the presentation, participants were guided to collaboratively think about the skills, resources, and support necessary to address the issues discussed.

These forums served two primary CBPR purposes: community collaboration with making sense of survey data and building LGBTQ community problem-solving discussions. The facilitated discussions provided an intimate, informal, and comfortable way for a diverse group of individuals and community members who identify as part of an LGBTQ community to meet and have their views heard on the survey data. Seasoned facilitators led the discussions within which participants expressed concerns about feeling supported and safe within the broader community, and also envisioned creative, realistic, and effective solutions for LGBTQ community-building. Through a meaningful collaboration of shared values and goals for community support, these forums fostered ideas for community engagement and sustainable local change. The forums also provided research data and moved forward to the CBPR-centered research agenda.

\section{Phase 3: Regional Summit}

The final phase of the project was a regional "LGBTQ Summit" that provided an opportunity for a broader range of community members to hear the results of the project and connect with each other to plan realistic actions responding to community needs identified by the survey and forums. The Summit was a oneday, five-hour event designed and facilitated by the organization that guided the community forums. The event was hosted in two locations, 70 miles apart, to encourage the participation of community members residing in the two distinct county regions. The two sites were linked via video-conferencing for the opening and closing presentations. Approximately 80 people attended the Summit; 20 in a northern location and 60 in a southern 
location in the county, a reflection of the more significant existing infrastructure in the south. The content of the Summit was driven by three critical needs identified through the survey and community forums: 1 ) increasing LGBTQ social opportunities, 2) addressing diversity within local LGBTQ communities, and 3) improving safety from discrimination and violence.

We used a range of strategies to invite community members to this action-based Summit. Partnership Council members created and distributed flyers in local businesses and at LGBTQ events, including a wellattended marriage equality leadership training, and created a website with information about the Summit. Council members, the research team, and LGBTQ community members publicized the event through personal and professional contacts. Members of the research team contacted local radio stations, newspapers, and LGBTQ list-serves to reach community members outside of established social networks and in more rural areas. Community forum participants who stated interest in further project information were invited to the Summit by email. Although it is difficult to imagine a time before social media communication, even in February 2009, when the Summit was held, mobile phones and social media were not widespread. Thus we relied on flyers, word of mouth, and emails to promote the event.

To begin the Summit, the first two authors co-presented the project overview and results via videoconferencing. Visuals, simple language, and songs were used to make the findings accessible to the community audience. Following the presentation, parallel activities were structured in the North and South county locations. Participants selected a priority area they were interested in working on. Action planning took place in small groups facilitated by experienced diversity trainers and included the following stages: developing a vision; case statement; goal setting; and resources, needs, and next steps. Finally, the participants reconvened via videoconferencing to share the action plans created by all groups. As group representatives presented and answered questions, facilitators documented the main ideas. Following the presentations, participants were given the opportunity to sign up to collaborate with groups formed across the county to take action on specific issues.

Summit participants demonstrated enthusiasm for the goals they developed and provided one another with thoughtful feedback about how best to attain them. Some breakout groups came up with a large goal, while others divided into sub-groups with smaller goals. Broader aspirations were priorities in South county, where there is more substantial infrastructure than in North county. For example, some South county participants envisioned building a centralized LGBTQ community and recreation center, and some North county participants created a plan for holding a monthly movie night and potluck in private residences. In the months following the Summit, some goals were met by planning groups and some action plans were incorporated into community agencies' work; other ideas were not sustained.

\section{Strengths, Challenges, and Strategies}

Strengths and Challenges of Each Project Component. In this section, we present the strengths of our project, the challenges we faced, and the strategies we developed to address these challenges. We discuss these ideas in terms of the three critical components of the project: the research infrastructure, the community partner agency, and efforts related to broader community engagement in each research phase.

Research Infrastructure. The project had a relatively robust research infrastructure consisting of two faculty members, six graduate students, federal funding for the first two years of the project, and the resources available at a Research I university. The researchers had a federal grant that supported the research aspects of the project and components of community engagement. The project originated with the researchers, who initiated contact with the community partner agency. We intentionally designed the complex multi-phase project knowing that it would demand significant time, coordination, and interpersonal investment to be successful.

Our dedication to CBPR's commitment to multi-vocal research practices, which we emphasized in each phase, provided a structure for decision-making and community participation. The priorities of the 
community participants, and our research team's responsiveness to these, reshaped the project's aims. Although the researchers had in mind a focus on LGBTQ mental health services, we learned quickly by meeting with the community partner organization staff, LGBTQ service providers, and community members, that this research priority would underlie the project but not frame it. Given the dearth of visibility and gathering spaces, community members were interested primarily in LGBTQ people's perceptions of their community, which was a broad focus that had mental health components embedded within it. In this way, the project successfully balanced researchers' academic priorities (research on compelling academic questions around LGBTQ social support and mental health) and diverse community members' needs (an assessment of LGBTQ community assets and risks).

Together, the project participants provided an outlet for LGBTQ community members through the Community Forums and Summit discussions, within which their voices were heard and actions collaborated on. The anonymous survey documented varied perspectives and served as the foundation for the design and content of the forums and Summit. We disseminated our research findings within the forums, designed to elicit input into our preliminary analysis of the information gathered in surveys, and to fill in any gaps. The project served to gather community voices, as well as act upon them.

Both of the PIs and several cohorts of trained research team members were involved with each phase of the research, and this level of immersion and coordination, although presenting challenging time-management demands for both for the PIs and the graduate students, was required to sustain the work over the 3.5 year period. Research team members were essential to completing the study, and the strength of the project was the researchers' ability to carry out the tasks associated with CBPR. This work was supported by significant university resources, including the second author's federal grant, which provided seed money, meeting space, survey consultants, computers, and photocopying. Our research team was composed of generous students willing to take on any work handed to them. Students conducted literature reviews of CBPR scholarship to understand the models' principles. In Phase 1, the research team collected survey instruments, collaboratively designed the survey, and interfaced with the UCSB Survey Center when the survey was posted online and piloted, revised, then distributed. The researchers identified as LGBTQ community members and allies and moved the project forward by reaching out to their social networks in the community, for example, by distributing surveys at LGBTQ community events. Research team members collaboratively organized Council meetings and community forums, analyzed survey data and helped set up the Summit. A significant outcome of this study's process was training graduate students in CBPR and experience with research that extend beyond "the lab" or "the ivory tower."

The research team's work was not limited to traditional research-related tasks, which ultimately taxed the energy of research team members and used their time in ways not always conducive to graduate research training. For example, Council and forum meetings required significant organization of carpooling, food orders (and pick up and delivery), and gift certificates. Graduate students performed most of these tasks, although they were not ideally suited to these roles, being relatively new to the region or unfamiliar with community organizing and cultivation of CBPR relationships.

Our attempts to include LGBTQ community participation in each stage of the research were not always successful. At the survey stage, our reliance on community researchers, which included the development of the training materials, the training itself, and trouble-shooting distribution and collection of surveys, was time-consuming, and the results were disappointing. The novice researchers were overly optimistic about how many surveys they could motivate others to complete within the project timeline. We received fewer surveys than expected using this strategy and had to discard several because respondents were not LGBTQ-identified. Although the community researchers did not significantly help us with our aim for better representation among specific LGBTQ sub-groups, their work did not hinder the researchers from obtaining a high number of surveys overall. Lessons learned were that considerable guidance and communication is needed to help community 
researchers succeed, and appropriate expectation must be set by the researchers, and that training should include shadowing seasoned researchers.

Community Partner. The community partner agency contributed to the project in a number of significant ways. Most importantly, as a highly visible, credible, and long-standing service provider, they conferred initial legitimacy to the project within the community. When working with a marginalized community that may be wary of researchers and exploitation, partnering with such an organization is essential to bring skeptical community members into a CBPR collaboration. The agency identified and reached out to volunteers, community leaders, and clients to participate in the Council. Simultaneously, we were aware that some individuals and sub-populations had negative assessments of or weak affiliations with the organization and would likely not participate. We took steps to work through other channels to encourage their participation in surveys, forums, and the Summit to have their voices heard.

The partner organization provided space for Council meetings within their two buildings in different parts of the county, which had comfortable meeting rooms and were familiar to many Council members. The organization staff also arranged for some Council meetings and our Council Retreat to be held at a church meeting room equipped with a kitchen, which made it easier for us to serve light meals. In addition, some of the Community Forums were held at the agency, again facilitating the meeting in a place that some people felt was "their own" and most comfortable and safe. These meeting spaces were essential because the meeting at the university was, for many community members, uncomfortable, inconvenient, and required paying for parking. Other central meeting spaces, such as library rooms, charged a fee that we did not have a budget for.

The community partner organization, although resource-poor, supported the CBPR project by administering the local grant we received, which relieved the research team from some tasks related to the Council, such as photocopying and reimbursements for food and travel expenses. The agency directly supported the research project through email blasts to its very large list-serve announcing the survey and providing links to it, as well as distributing paper surveys at its two locations and Pride event. The Community Forums and LGBTQ Summit were also announced on the listserv. Research project success is seen most clearly in two actions taken by the partner organization following the Summit. First, the Board funded an LGBTQ Mental Health Wellness Coordinator position (currently with the job title LGBTQ+ Program Manager) to organize and promote mental health services at the partner agency and to conduct community outreach throughout the county. Second, the organization pursued one of the main findings of the research, community members' desire for local organizations to work on safety from harassment and violence, and initiated dialogue with the Chief of Police that resulted in mandatory trainings for local law enforcement (Israel, Harkness, Delucio, Ledbetter, \& Avellar, 2014).

Broader Community Engagement. The community engagement of the project occurred primarily through the Partnership Council, community researchers, community forums, and the regional Summit. Partnership Council members provided a range of contributions that sustained the project through strategizing about how best to include diverse research participants, and directly recruiting participants to attend the community forums, an essential vehicle for hearing individual interpretations of the survey information we had collected. Over the course of the project, council members offered essential resources, including contacts with their social and professional networks, graphic design expertise, and the generous hosting of forums at a home, restaurant, or agency.

We faced challenges in developing community leadership capacity and buy-in to the project, despite the fact that the Partnership Agreement provided new members with a clear sense of the responsibilities of Council membership. There was not an existing LGBTQ community voice, so we put energy into community and leadership development, mainly because efforts were focused on engaging people who were not already at the table. A few vocal individuals did not have the patience for the process aspect of collaboratively creating a community research strategy and urged the researchers to make decisions and lead the group, but the researchers were reluctant to do so due to their commitment to community engagement. Similar requests have 
been documented in other CBPR studies with LGBTQ communities (see Holtby, Klein, Cook, \& Travers, 2015). The membership of the Council, EC, and research team changed over time in keeping with individuals' availability, interest, and energy. We faced particular difficulty with creating a Council representative of diverse constituencies that allowed disenfranchised individuals to share an equal voice with more privileged members. One barrier to the fullest and most representative community participation was the lack of connectedness, visibility, and safety of some segments of LGBTQ communities. For example, some LGBTQ individuals (primarily middle-aged to older, partnered lesbian and gay male) feel assimilated into the lesbian/gay and heterosexual communities. However, accounts we heard reflected victimization and isolation experienced by newcomers to the community, youth, transgender individuals, and people of color. These characteristics are exacerbated in North county due to the socially and politically conservative nature of the area.

We sought assistance with building and maintaining a diverse and consistent Partnership Council, and received a $\$ 10,000$ community grant run through the Partner organization. The grant support moved us toward the overarching goal of community-building and specifically assisted our efforts to sustain current members' involvement and to encourage the participation of marginalized individuals, including youth, Latino/ individuals, rural residents, and transgender/genderqueer persons. The grant was run through the Partner organization and enabled more Council members to attend and participate in meetings. Council members could receive reimbursement for transportation to and from Council meetings, childcare reimbursement, and a conference call telephone system. The grant also covered light meals that fostered a sense of community at our meetings.

This grant support also allowed us to contract with a local organization that focuses on equity and inclusion to assist us in building a sustainable, diverse, and directed Partnership Council. Attending Council meetings, consultants assessed the composition of the Council, individuals' participation in discussions, and their decision-making was influenced by gender, ethnicity, age, gender identity, SES, dis/ability, and other power differentials. Next, they consulted with the Executive Committee, recommended additional Council members to increase diversity, and facilitated a full-day retreat for the Council to determine a project name, Mission Statement, and Vision Statement. Naming the project and building consensus about the mission and vision marked a high point of Council cohesion and facilitated increased visibility of the group, legitimating the group itself and the survey and forums to be conducted.

Our contract with the equity and inclusion training organization assisted us by addressing the ongoing challenge we faced with bringing in voices of people not already at the table as highly-vocal community members or LGBTQ service providers. We reached out to those from marginalized LGBTQ sub-groups, such as newcomers, youths, Spanish-speakers, and transgender individuals. To ensure inclusivity, we worked deliberately toward diversity within Council members, survey respondents, and community forum participants. Significant attempts to include Spanish-speaking LGBTQ individuals had limited success, yet concerted work to invite transgender participants met with success.

Council members reflected diversity in terms of gender, gender identity/expression, economic status, ethnic group membership, culture, age, HIV status, mental health consumer status, and physical abilities. To promote diversity and enhance trust, EC and Council members personally invited others to join the group. A particular challenge we faced is that the LGBTQ community is small, with many relationship interconnections and differing degrees of "outness." We took care to invite members who would work well with the others on the Council and be comfortable with visibly being part of an LGBTQ project. At the same time, we were aware that our sensitivity to maintaining positive group dynamics and LGBTQ-community affiliation did bar some individuals from participating.

Council members assisted the development of the forums, such as by insisting that researchers talk about research in an accessible way in both the language used in the survey and discussion of the results. The forums served two purposes: 1) community collaboration with making sense of survey data, and 2) building LGBTQ community problem-solving discussions. The facilitated discussions provided an intimate, informal, and comfortable way for a diverse group of individuals and community members who identify as part of an 
LGBTQ community could meet one another and have their views heard on the survey data. Led by seasoned facilitators, participants expressed needs and concerns about feeling supported and safe within the broader community and also envisioned creative, realistic, and effective solutions for LGBTQ community-building. Through a meaningful collaboration of shared values and goals for community-support, these forums fostered community engagement and sustainable local change. The forums also provided research data and also moved forward to the CBPR-centered research agenda.

Following the Forums, the Council worked on brainstorming ideas about how to bring the 3.5-year project to a conclusion when it was clear that funding was not received to continue it. Our Council discussions resulted in the collaborative design and planning of the LGBTQ Summit around three research findings, and Council members worked to promote the event with eye-catching flyers and a Facebook page. The result was a Summit event that felt "owned" by the Council as a whole.

Negotiating Roles and Relationships among Project Components. Negotiating roles, responsibilities, resources between the academic and community partner were challenging, and required strategies to address. An experienced CBPR research we consulted with early in the project emphasized the importance of working with a community entity as a full and equal partner with the researchers (P. Koegel, personal communication). At the time the project started, the partner organization was struggling in a time of severe economic downturn and budget cuts. The organization could not devote significant staff time to the project, however, shared work with the research team by copying handouts and providing meeting spaces, and upon receiving the community grant, staff members were responsible for travel, childcare, and meal reimbursements to Council members.

There were other resource imbalances between the academic and community partners over the course of the project. The two researchers and one community agency administrator were engaged throughout, but due to staff turnover, the director of counseling services position was held by several individuals over the course of the project. Furthermore, the researchers' institution viewed this project as central to their work expectations, so they were able to put considerable energy into the project, unlike the community partners. Ideally, the primary connection with Council members and the meeting coordination would have been the responsibility of the community partner. However, due to the organization's severely limited infrastructure and budget, this division of duties was not possible.

Attending to Diversity within LGBTQ Communities. Based on the perspectives of Council members and the diversity consultants, we knew we needed to reach out to LGBTQ community members who are most comfortable speaking/reading Spanish. To facilitate Spanish speakers' inclusion, we spent a great deal of time developing English and Spanish versions of the online and paper surveys and facilitated one community forum in Spanish. At the Summit, a Spanish interpreter was present at both sites, and written materials were available in Spanish and English. Despite these efforts to facilitate communication, some of the surveys returned in Spanish could not be used because respondents did not identify as LGBTQ, yielding only seven usable surveys in Spanish. Creating resources was not enough, and we needed consistent efforts from Spanish-speaking LGBTQ community members themselves - not service providers to them - to closely align with the project. Further, an impediment to reaching Spanish speakers is that they may not identify as part of the LGBTQ community or feel safe to disclose.

We had multiple strategies to include and acknowledge transgender participants of different ages. The Partnership Council had transgender members, we conducted two forums, including transgender support group members in two regions, and we altered restroom signs at the LGBTQ Summit locations as all-gender. One research team member devoted time to outreach to transgender individuals and advocates. Some outspoken and visible transgender individuals connected to LGBTQ services participated, and they reported that other transgender individuals were significantly underrepresented. Two potential reasons for this may be the feeling by some that the LGBQ community does not openly welcome them, and that post-transition, an individual may not wish to be visible or identified as transgender. 
Throughout the project, we also were attentive to LGBTQ individuals with various physical abilities. We had a Partnership Council member with low vision, ensured our meeting sites were accessible, and handouts were made available in a large font format.

At every stage, we were sensitive to participants' different comfort levels with and LGBTQ-community connection and took extra efforts to ensure anonymity when it was desired. At the Summit, photographs were taken by an LGBTQ community member volunteer, but they could only be taken of participants who signaled consent to be photographed by wearing a red sticker. No complaints were voiced about this system. Further, we opted not to audiotape the forums in order to enhance trust within the group that information would not be associated with specific individuals. The downside of not audiotaping was that our note-takers were not professional stenographers, and it was challenging work to document a discussion that involved multiple voices. The lack of verbatim quotes from participants meant that analysis of the forum data could not be as systematic or precise as an analysis of the survey data.

\section{Sustaining the Project}

Funding. A significant challenge of our research process was securing funding. Concurrent with these stages, the Council provided feedback on a National Institutes of Health Exploratory/Development (R21) grant proposal that had been submitted by the research team, but not funded. A revised and resubmitted proposal to the National Institute of Mental Health (NIMH) aimed at reducing mental health disparities by comparing LGBTQ mental health/social support service models. We planned to use a CBPR infrastructure to support the research and aimed to provide capacity-building with a diverse LGBTQ community. When this funding attempt failed, we designed Phase 3 of the project, bringing our work to a highly productive close at a day-long Summit meeting. Without a large-budget grant that would support ongoing efforts and full-time staff devoted to the project on the community partner side, we resorted to completing the work and hosting the Summit by applying for smaller grants from the university for the research side and community foundations and student organizations for community engagement component. Although the Partnership Council could have continued without funding after the Summit, creating one ongoing entity was not a goal of the project, nor would it have served the community in significantly different ways than achieved by the partner agency.

Community infrastructure. Community development was the central focus of our research process. Starting the forums with an opening activity rather than jumping right into survey results urged participants to reflect on their relationship to the LGBTQ community and to create a sense of collective purpose. At the Summit, we encouraged communication and collaboration among participants through the structuring of the small groups around shared interest areas and the use of skilled facilitators.

Sustained action. There were several challenges to sustaining the action plans developed at the LGBTQ Summit. The goals or projects were intended to be developed and maintained solely using the resources within the group that designed it. Without avenues to obtain funding, realistic anticipation of and planning around potential obstacles, or an organized way to connect with other Summit groups or projects, some plans were dissolved, and interventions discontinued.

Furthermore, some projects became more complicated over time than were initially anticipated and could no longer be sustained with the resources of a small number of volunteers. One group met biweekly for three months to organize an emergency resource list specific to LGBTQ-identified people. Though the goal initially seemed simple enough, the scope of the project grew as more questions arose about what qualified a specific doctor, lawyer, housing shelter, or mental health professional to be on the list, how the list was to be updated over time, and how it would be distributed. As the project expanded, many volunteers stopped completing tasks or attending meetings, which increased responsibility on the few who remained. When central group members were unable to meet for a period of time, the group stopped meeting altogether, and the project was seriously threatened. If core members had brainstormed about potential obstacles prior to meeting with other volunteers, additional preventive planning could have occurred. Fortunately, funding was later received 
by the non-profit partner organization to hire a part-time mental health wellness coordinator who took the lead in creating and distributing the emergency responder list. This coordinator met with core group members to discuss the obstacles the project faced.

Training of law enforcement was another form of action that sustained to completion of some goals. As mentioned earlier, the Executive Director of the community partner organization shared data with the Chief of Police that was generated by the project. In response to information that the number one priority of the local LGBT community was freedom from harassment and violence, the Chief mandated a 5-hour training on LGBT issues for every sworn officer in the local community. The researchers and community partner organizations invited into the collaboration the police department and another community organization that specialized in equity and diversity training. Limited funding was secured from a local foundation, although most of the labor was donated by individuals and organizations. Additional data were collected to inform the design and content of the training, and approximately 150 law enforcement officers received the training. The researchers published several manuscripts from this project, including a report on the efficacy of the intervention (Israel, et al., 2014), an analysis of the ways in which participants demonstrated resistance and receptiveness to the training (Israel et al., 2017), and a description of LGBT-affirming law enforcement tactics generated by the participants (Israel, et al., 2016).

Finally, a significant barrier to sustainable change was the lack of a systematized way for Summit groups or projects to connect with one another at a time when social media networking was not widespread as it is today. This made it difficult for participants to share resources, attend each other's social events or meetings, and remain connected. During their presentations, representatives from each group stated the date, time, and location of the next meeting. This was the only way to follow up with most groups. In order to sustain interventions that are developed out of a large meeting, we recommend a centralized and shared social media format that allows groups and individuals to post their contact information, needs, progress, or events and access postings by other groups. The downside to such shared communication (at the time of writing, Facebook, Slack, group text messages, and shared Google calendars are some of the options) this is that those who are not comfortable being identified with an LGBTQ identity or issue may find this the lack of anonymity to be a disincentive.

\section{Implications for Counseling and Psychology}

In addition to focusing on individual mental health treatment, the fields of counseling and psychology provide frameworks for identifying and addressing structures that contribute to mental health challenges. In fact, advocacy competencies have been identified as an "ethical aspect of service to clients" by Toporek, Lewis, and Crethar (2009, p. 260), who outlined six domains of social justice advocacy for counselors. One of these domains, community collaboration, involves counselors and psychologists assisting community groups in achieving their goals, with the community taking the lead in how problems are addressed. A number of challenges and obstacles arise, however, that prevent counselors and psychologists from effectively partnering with communities toward shared goals. These can include the considerable time commitment these relationships entail, distrust of psychologists among community members, compassion fatigue and burnout, lack of control in the project, and uncertainty about the outcome (Varghese et al., in press). We hope that lessons learned from this CBPR project can provide guideposts that help counselors and psychologists navigate collaborations with individuals, groups, and organizations within their local communities.

\section{Conclusion}

Our 3.5-year CBPR project experience motivates us to share lessons learned with other researchers who seek to work with invisible, geographically-dispersed communities, which may be as wide-ranging as people with disabilities, unpaid caregivers for elderly people, and parents raising children diagnosed with autism. Our recommendations focus on relationships between researchers and CBPR participants, identifying the different responsibilities of academic researchers and community partners, setting appropriate expectations for research 
and community engagement, and assessing the CBPR process throughout each stage of the project.

When establishing an advisory committee, we found that attention must be paid by all members to the intentional recruitment of key stakeholders and people who are embedded in diverse parts of the community to ensure inclusive representation. Conversations from the beginning of a project are best to set agreed-upon expectations for shared responsibilities based on the skills that the community partner and each Advisory Committee member can contribute based on community networks rather than the identities that they bring to the table, which can be tokenizing. Valuing individual contributions enhances attention to diversity and can minimize divisions between academic researchers and community participants.

At the same time, researchers do have needs and interests that differ from those of project participants. For the researchers, we found that appropriate expectations include spending time in the community to build relationships and the understanding that compared to other methods, CBPR scholars have less control of the research process because it is negotiated with a number of people in a sophisticated community setting. We recommend that researchers maintain research goals for academic publications while simultaneously participating in community-building activities that do not result in mainstream scholarly products. To be successful, researchers must design the project's scope at a level that they can invest in, and researchers should have honed some negotiation skills to protect their research goals and to motivate shared goals - for example, partnering on a collaborative component early on in the project to meet shared goals. On the communitybuilding side, we designed the Partnership Agreement, and on the research side, we sought feedback from community partners on the survey draft before completing it.

Ideally, a CBPR project will have a robust research infrastructure, a community partner with resources, and a community with an organized infrastructure in place. When this is not already in place, we recommend that the collaborators commit to building it as part of the project itself. Although our project worked with the "LGBTQ community," that community is not unified, located in a geographic area, or with vocal community organizers who are key players in bringing individuals together. Given this reality and characteristic of the CBPR method, rather than study LGBTQ individuals, this research cultivated community participation in all phases.

Trust-building is part of the CBPR process at each stage of the project, and researchers should build in time and energy to be engaged with the community. Academics must prove that they can listen, show up, and care about the people and community issues beyond the research project. Researchers develop partnerships by participating in community organizations' events, developing social relationships with members and leaders, and investing in the organizations and the people within them. We recommend that researchers rely on their personal contacts to routinely reach out to community leaders and participants as individuals by phone and in person, instead of relying on group email communication.

Collaboration and assessment of the project at each step of our project was productive, and we relied on a range of methods, including community forums, LGBTQ Summit, and a survey that itself engaged community in meaningful and enthusiastic ways. To accommodate different learning styles and communicate across distance, we used a combination of PowerPoint Presentations, teleconferencing, email, and interactive meeting methods. When assessing each step, it is essential to remember that the community participants live on a different timeline than academics do (we expect IRB approval wait time, long review periods for fund seeking review, calls for grant submission revision, and other steps that interrupt the flow of the work). To avoid impatience, we suggest that researchers have a variety of goals throughout the project staged to address the immediate needs of the community.

Another area of recommendations focuses on research and leadership participation. When facing the problem of a lack of representation of diverse sub-groups within the overall community (for example, transgender individuals were particularly challenging to recruit and required concerted outreach efforts in our study), resources must be devoted to specific outreach to engage those groups that are marginalized in the mainstream LGBTQ community. Further, we recommend securing adequate funding and meeting spaces to encourage the 
sustainability of projects designed as a result of a CBPR project. this creates more equitable participation by community members who have varied financial resources and volunteer time to enact sustainable change. From the start, researchers ought to develop realistic expectations for what each player can contribute to the project and dedicate time and resources to developing the capacity of community partners. On the researcher's side, infrastructure includes funding to support graduate students and hiring those who are invested not just in the project, but also in the community. On the Advisory Board side, members should commit time to the project and relationship-building beyond meeting time. When expectations are transparent in the Partnership Agreement, revisiting and even revising it over the project period will assist in mitigating any accountability imbalances. We found it crucial for all participants to understand that significant collaborative efforts would have to be made to cultivate a diverse range of networks in both visible and invisible communities. At the later stages of the research to bridge the research and community members, the CBPR team can acknowledge the perspectives of people involved in the project (e.g., participants, community partners, researchers), by inviting community partners and participants to review an initial draft of the manuscript (which we did) or executive summary and share their reactions and perspectives that researchers can then use to revise the work.

Overall, this CBPR project brought together facets of a diffuse LGBTQ community to better understand the primary needs of the community as a whole and mobilize community members and leaders toward datadriven social actions. It is our belief that the full impact of this collaboration goes beyond concrete outcomes and continues on in unmeasurable ways. For example, the sharing of ideas and networking among local LGBTQ people allowed for allyship and ongoing partnerships and facilitated community members taking on new roles and gaining skills in activism and research as a form of empowerment. Although we had not envisioned it at the start of our CBPR process, the LGBTQ Summit event served both as closure for the research arm of the study and as a forward-looking community action event. We recommend a similar model for other researchers because it reflects the CPBR balance between research and community engagement. Finally, we note that this project was among the most rewarding of our careers, and we encourage other researchers to team up with marginalized communities, particularly those that are invisible and dispersed, to share ideas, skills, and resources that enhance inclusive and equitable community capacities.

\section{Corresponding Author}

Laury Oaks, Professor, and Chair, Department of Feminist Studies, University of California, Santa Barbara, CA 93106. Electronic mail may be sent to oaks@femst.ucsb.edu.

\section{Acknowledgement}

This project was supported by National Institute of Mental Health Grant K01MH063305, UCSB Institute for Social, Behavioral, and Economic Research, UCSB Academic Senate, and the Fund for Santa Barbara. Appreciation is extended to all of the community member participants, Pacific Pride Foundation, the Partnership Council, Just Communities, and the rest of the research team. 


\section{References}

Altheide, D. (1987). Ethnographic content analysis. Qualitative Sociology, 10, 65-77.

Angell, K.L., Kreshka, M.A., McCoy, R., Donnelly, P., Turner-Cobb, J. M., Graddy, K., Kraemer, H.C., \& Koopman, C. (2003). Psychosocial intervention for rural women with breast cancer. Journal of General Internal Medicine, 18, 499-507.

Bauermeister, J. A., Pingel, E. S., Sirdenis, T. K., Andrzejewski, J., Gillard, G., \& Harper, G. W. (2017). Ensuring community participation during program planning: Lessons learned during the development of a HIV/ STI program for young sexual and gender minorities. American Journal of Community Psychology, 60, 215-228. doi:10.1002/ajcp.12147

Becker, A.B., Israel, B.A. \& Allen III, A.J. (2005). Strategies and techniques for effective group process in CBPR partnerships. In B. A. Israel, E Eng, A. J Schulz, and E.A. Parker (Eds.). Methods in community-based participatory research for health (pp. 52-72). San Francisco: Jossey-Bass.

CCPH (Campus-Community Partnerships for Health). (2000). Partnership Perspectives, 1(2). Retrieved from http://depts.washington.edu/ccph/pdf_files/summer1-f.pdf

Chung, B., Corbett, C.E., Boulet, B., Cummings, J.R., Paxton, K., McDaniel, S., Mercier, Charla Franklin, S.O., Mercier, E., Jones, L., Collins, B.E., Koegel, P., Duan, N., Wells, K.B., \& Glik, D.C. (2006). Talking wellness: A description of a community-academic partnered project to engage an African-American community around depression through the use ofpoetry, film, and photography. Ethnicity and Disease, 16, suppl. 1, p. S1-67-S1-78.

Clements-Nolle, K. \& Bachrach, A.M. (2008). CBPR with a hidden population: The transgender community health project a decade later. In Community-based participatory research for health, (2nd ed.) M. Minkler and N. Wallerstein,(Eds.) pp. 137-147. San Francisco: Jossey-Bass.

Dobinson, C., MacDonnell, J., Hampson, E., Clipsham, J., \& Chow, K. (2005). Improving the access and quality of public health services for bisexuals. Journal of Bisexuality, 5, 39-78.

Dworkin, S.H. \& Yi, H. (2003). LGBT Identity, violence and social justice: The psychological is political. International Journal for the Advancement of Counseling, 25, 269-279.

Elmslie, B. \& Tebaldi, E. (2007). Sexual orientation and labor market discrimination. Journal of Labor Research, 28, 436-453.

Fountain, C. A., \& Evans, D. B. (1994). Beyond shared rhetoric: A collaborative change model for integrating preservice and inservice urban educational delivery systems. Journal of Teacher Education, 45, 218.

Friedman, M. S., Koeske, G. F., Silvestre, A. J., Korr, W. S., \& Sites, E. W. (2006). The impact of gender-role nonconforming behavior, bullying, and social support on suicidality among gay male youth. Journal of Adolescent Health, 38, 621-623.

Graziano, K. J. (2004). Oppression and resiliency in a post-apartheid South Africa: Unheard voices of black gay men and lesbians. Cultural Diversity \& Ethnic Minority Psychology. Special Issue: Lesbian, Gay, and Bisexual Racial and Ethnic Minority Individuals: Empirical Explorations, 10, 302-316.

Hergenrather, K. C., Geishecker, S., Clark, G., \& Rhodes, S. D. (2013). A pilot test of the HOPE intervention to explore employment and mental health among African American gay men living with HIV/AIDS: Results from a CBPR study. AIDS Education \& Prevention, 25, 405-422. doi:10.1521/aeap.2013.25.5.405

Holtby, A., Klein, K., Cook, K., \& Travers, R. (2015). To be seen or not to be seen: Photovoice, queer and trans youth, and the dilemma of representation. Action Research, 13, 317-335. doi: $10.1177 / 1476750314566414$ 
Irwin, J. A., Coleman, J. D., Fisher, C. M., \& Marasco, V. M. (2014). Correlates of suicide ideation among LGBT Nebraskans. Journal of Homosexuality, 61, 1172-1191. doi:10.1080/00918369.2014.872521

Israel, B. A., Schulz, A. J., Parker, E. A., Becker, A. B., Allen, A. J., \& Guzman, J. R. (2003). Critical issues in developing and following community based participatory research principles. In M. Minkler and N. Wallerstein (Eds.), Community-based participatory research for health (pp. 53-76). San Francisco: Jossey-Bass.

Israel, B. A., Eng, E., Schulz, A. J., \& Parker, E. A. (2005). Methods in community-based participatory research for health. San Francisco: Jossey-Bass.

Israel, T., Bettergarcia, J. N., Delucio, K., Avellar, T. R., Harkness, A., \& Goodman, J. A. (2017). Responses of law enforcement to LGBTQ diversity training. Human Resource Development Quarterly, 28, 197-226. doi: 10.1002/hrdq.21281

Israel, T., Harkness, A., Avellar, T. R., Delucio, K., Bettergarcia, J. N., \& Goodman, J. A. (2016). LGBTQaffirming policing: Tactics generated by law enforcement personnel. Journal of Police and Criminal Psychology, 31, 173-181. doi: 10.1007/s11896-015-9169-2

Israel, T., Harkness, A., Delucio, K., Ledbetter, J. N., \& Avellar, T. R. (2014). Evaluation of police training on LGBTQ issues: Knowledge, interpersonal apprehension, and self-efficacy. Journal of Police and Criminal Psychology, 29, 57-67. doi:10.1007/s11896-013-9132-Z

Lehavot, K., Balsam, K.F., and Ibrahim-Wells, G.D. (2009). Redefining the American quilt: definitions and experiences of community among ethnically diverse lesbian and bisexual women. Journal of Community Psychology, 37, 439-458.

Marshall, Z., Nixon, S., Nepveux, D., Vo, T., Wilson, C., Flicker, S., \& Proudfoot, D. (2012). Navigating risks and professional roles: Research with lesbian, gay, bisexual, trans, and queer young people with intellectual disabilities. Journal of Empirical Research on Human Research Ethics, 7(4), 20-33. doi:10.1525/jer.2012.7.4.20

McDaniel, S., Jones, L., Koegel, P., \& Wells, K.B. (2006). Witness for wellness: Preliminary findings from a community-academic participatory research mental health initiative. Ethnicity and Disease, 16(1) suppl. 1, S1-18-S1-34.

Meyer, I. H. (2003). Prejudice, social stress, and mental health in lesbian, gay, and bisexual populations: conceptual issues and research evidence. Psychological Bulletin, 129, 675-697.

Minkler, M. (2005). Community organizing and community building for health. New Jersey: Rutgers University Press.

Minkler, M. \& Wallerstein, N. (2008). Community-based participatory research for health: From process to outcomes (2nd ed.). San Francisco, CA: Jossey-Bass.

Minkler, M., Wallerstein, N., \& Hall, B. (2002). Community-based participatory research for health. San Francisco, CA: Jossey-Bass.

Minkler, M., \& Hancock, T. (2003). Community-driven asset identification and issue selection. In M. Minkler \& N. Wallerstein (Eds.), Community-based participatory research for health (pp. 135-154). San Francisco, CA: Jossey-Bass.

O’Toole, T.P., Aaron, K.F., Chin, M.H., Horowitz, C., \& Tyson, F. (2003). Community-Based participatory research: opportunities, challenges, and the need for a common language. Journal of General Medicine, $18,592-594$. 
Paxton, K. C., Guentzel, H., \& Trombacco, K. (2006). Lessons learned in developing a research partnership with the transgender community. American Journal of Community Psychology, 37(3-4), 349-356.

Peterson, J. L., Folkman, S., \& Bakeman, R. (1996). Stress, coping, HIV status, psychosocial resources, and depressive mood in African American gay, bisexual, and heterosexual men. American Journal of Community Psychology, 24, 461-487.

Proescholdbell, R. J., Roosa, M. W., \& Nemeroff, C. J. (2006). Component measures of psychological sense of community among gay men. Journal of Community Psychology, 34, 9-24.

Rhodes, S. D., Alonzo, J., Mann, L., Downs, M., Simán, F. M., Andrade, M., \& Bachmann, L. H. (2014). Novel approaches to HIV prevention and sexual health promotion among Guatemalan gay and bisexual men, MSM, and transgender persons. AIDS Education and Prevention, 26, 345-361. doi:10.1521/aeap.2014.26.4.345

Rhodes, S. D., Yee, L. J., \& Hergenrather, K. C. (2006). A community-based rapid assessment of HIV behavioural risk disparities within a large sample of gay men in southeastern USA: A comparison of African American, Latino and white men. AIDS Care, 18, 1018-1024.

Ridley, D. A. (1997). Using local research to change 100 communities for children and family. American Psychologist, 52, 424-433.

Rodríguez-Díaz, C. E., Martínez-Vélez, J. J., Jovet-Toledo, G. G., Vélez-Vega, C. M., Hernández-Otero, N., Escotto-Morales, B., \& Mulinelli-Rodríguez, J. J. (2016). Challenges for the well-being of and health equity for lesbian, gay, and bisexual people in Puerto Rico. International Journal of Sexual Health, 28(4), 286-295. doi:10.1080/19317611.2016.1223252

Saranson, I. G., Saranson, B. R., Shearin, E. N., Pierce, G. R., (1987). A brief measure of social support: practical and theoretical implications. Journal of Social and Personal Relationships 4, 497-510.

Szymanski, D., \& Kashubeck-West, S. (2008). Mediators of the relationship between internalized oppressions and lesbian and bisexual women's psychological distress. The Counseling Psychologist, 36, 575-594.

Tanner, A. E., Mann, L., Song, E., Alonzo, J., Schafer, K., Arellano, E., \& Rhodes, S. D. (2016). weCARE: A Social media-based intervention designed to increase HIV care linkage, retention, and health outcomes for racially and ethnically diverse young MSM. AIDS Education \& Prevention, 28(3), $216-$ 230. doi:10.1521/aeap.2016.28.3.216

Toporek, R. L., Lewis, J. A., \& Crethar, H. C. (2009) Promoting systemic change through the ACA Advocacy Competencies. Journal of Counseling and Development, 87, 260-268.

Travers, R., Pyne, J., Bauer, G., Munro, L., Giambrone, B., Hammond, R., \& Scanlon, K. (2013). 'Community control' in CBPR: Challenges experienced and questions raised from the Trans PULSE project. Action Research, 11, 403-422. doi:10.1177/1476750313507093

U.S. Census Bureau. (2006). County Census Information. Retrieved from http://quickfacts.census.gov/qfd/ states/06/06083.html

Varghese, F. P., Israel, T., Seymour, G., Herbst, R., Suarez, R., \& Hargons, C. (in press). Injustice in the justice system: Reforming inequities for true "justice for all." The Counseling Psychologist.

Wallerstein, N. and B. Duran (2006). Using community-based participatory research to address health disparities. Health Promotion Practice, 7, 312-323.

Walter, C. L. (2004). Community building practice: A conceptual framework. In M. Minkler (Ed.), Community organizing and community building for health (pp. 66-78). New Brunswick, NJ: Rutgers University Press. 
Wells, K.B., Staunton, A.D., Norris, K.C. Bluthenthal, R.N., Chung, B., Gelberg, L., Jones, L. Kataoka, S.H., Koegel, P., Miranda, J., Mangione, C., Patel, K., Rodriguez, M.A.,. Shapiro, M.F. \& Wong, M. (2006). Building an academic-community partnered network for clinical services research. Ethnicity and Disease, 16(1) suppl. 1, S1-3-S1-17.

Wells, K and Norris, KC (eds.). (2006). The community health improvement collaboration: Building community-academic partnerships to reduce disparities. Ethnicity \& Disease, 16(1, Suppl. 1).

Willging, C. E., Salvador, M., \& Kano, M. (2006). Unequal treatment: Mental health care for sexual and gender minority groups in a rural state. Psychiatric Services, 57, 867-870.

Zillow, Inc. (2018a). Santa Barbara home prices \& values. Retrieved from https://www.zillow.com/santabarbara-ca/home-values/.

Zillow, Inc. (2018b). Santa Barbara home prices \& values. Retrieved from https://www.zillow.com/santamaria-ca/home-values/. 